\title{
Health-related quality of life in patients with polycystic ovary syndrome: validation of the German PCOSQ-G
}

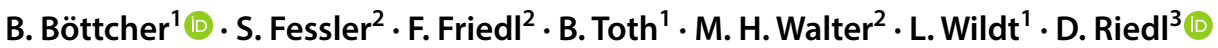

Received: 29 August 2017 / Accepted: 6 December 2017 / Published online: 16 December 2017

(c) The Author(s) 2017. This article is an open access publication

\begin{abstract}
Purpose Patients with polycystic ovary syndrome (PCOS) report a decreased health-related quality of life (HRQOL) and higher levels of psychological distress. Validated questionnaires are necessary to assess the impact of PCOS on patients' lives. The aim of the present study was to evaluate the German "Polycystic Ovary Syndrome Questionnaire" (PCOSQ-G). Methods The psychometric properties of the PCOSQ-G were investigated in PCOS patients with item-total correlation, internal consistency and test-retest reliability. Correlations with the Short-Form-36 Health Survey (SF-36) and the Hospital Anxiety and Depression Scale (HADS-D) were calculated to evaluate the validity of the PCOSQ-G. Discriminatory validity was investigated through a receiver operating characteristic curve and independent sample $t$ tests compared with healthy controls.

Results Good psychometric properties were found for most items. Acceptable to high internal consistency was found for the total score $(\alpha=0.94-0.95)$ and all subscales $(\alpha=0.70-0.97)$. High test-retest reliability was found for the total score $(0.86)$ and all subscales (0.81-0.90). The validity analyses showed that the PCOSQ-G total score was positively correlated with both SF-36 summary scales and was negatively correlated with both HADS subscales. Patients reported significantly lower values for the PCOSQ-G total score $(p<0.001)$ and all subscales, and the PCOSQ-G discriminated well between patients and healthy controls (AUC $=0.81, p<0.001$ ).

Conclusions PCOSQ-G is a reliable and valid tool to assess the HRQOL in patients with PCOS and can be used in future clinical research. Patients with PCOS exhibited an impaired HRQOL, which indicates the need for psychosomatic counseling.
\end{abstract}

Keywords Polycystic ovary syndrome $\cdot$ Quality of life $\cdot$ Anxiety $\cdot$ Depression $\cdot$ PCOSQ $\cdot$ PCOSQ-G validation

Electronic supplementary material The online version of this article (https://doi.org/10.1007/s00404-017-4623-2) contains supplementary material, which is available to authorized users.

D. Riedl

david.riedl@i-med.ac.at

1 Department of Gynecological Endocrinology and Reproductive Medicine, Medical University Innsbruck, Anichstrasse 35, 6020 Innsbruck, Austria

2 Department of Psychology, University of Innsbruck, Bruno-Sander-Haus, Innrain 52f, 6020 Innsbruck, Austria

3 University Clinic of Medical Psychology, Medical University Innsbruck, Schöpfstr. 23a, 6020 Innsbruck, Austria

\section{Introduction}

Polycystic ovary syndrome (PCOS) is a common endocrine disorder that affects up to $12 \%$ of women of reproductive age [1-3]. Following the Rotterdam criteria, PCOS is characterized by oligo- or anovulation, clinical or biochemical aspects of hyperandrogenism and the presence of polycystic ovaries on ultrasound [4]. A growing body of evidence suggests that impaired mental health and a reduced health-related quality of life (HRQOL) may be significantly associated with this disorder $[5,6]$. More specifically, several studies in different patient populations and meta-analyses of these studies have shown that women with PCOS have an increased risk of anxiety and depression symptoms [5, 7-17] and a reduced HRQOL [18-23]. These scores are higher than those of healthy controls, but nevertheless are usually within the normal range [7, $8,12]$. Additionally, in the current studies, the percentage 
ranges of women affected by anxiety and depression are extremely variable, especially when subgroup analyses are performed based on the body mass index and clinical signs of hyperandrogenism [24-30].

Due to these conflicting results, we aimed to examine our own patient cohort with PCOS and hypothesized that our patients would show higher depression and anxiety scores and a reduced HRQOL.

While generic instruments to assess HRQOL allow to compare the impairing effects of different physical diseases, they do not cover all central areas of health and well-being of PCOS. The health-related quality of life questionnaire for women with PCOS (PCOSQ) is a disease-specific, validated questionnaire developed by Cronin et al. [31]. The PCOSQ consists of 26 items that are categorized into five domains after factor analysis (emotion, hirsutism, weight, infertility, and menstruation). The questionnaire takes $10-15 \mathrm{~min}$ to complete. To date, the questionnaire has not been used in German-speaking countries. Its distinctive feature is the revelation of disease-specific impairments and symptoms like hirsutism, infertility or menstrual irregularities which occur in PCOS patients.

The main objective of this study was to validate a German version of the PCOSQ and to confirm its reliability to facilitate further studies in German-speaking populations.

\section{Methods}

\section{Patients and procedures}

Patients $(n=199)$ aged between 18 and 45 years who were diagnosed with PCOS were recruited from the outpatient department of the University Clinic of Gynecologic Endocrinology and Reproductive Medicine Innsbruck, Austria, between 2012 and 2014. The medical history and sociodemographic data were collected in personal interviews and with self-administered questionnaires. PCOS was diagnosed according to the Rotterdam criteria [4]. No specific exclusion criteria except for scarce German language skills were applied. A healthy control sample of women within the same age group recruited in a student cohort via internet had the option to return an online version of the questionnaire. The patients and controls received a questionnaire battery that took approximately $40 \mathrm{~min}$ to complete. The patients received the PCOSQ again after 4 weeks for validation of the questionnaire.

The study was conducted in accordance with the Declaration of Helsinki. The Ethics Committee of the Medical University Innsbruck approved the study design (AN-5233329/4.14). Written informed consent was obtained from all participants.

\section{Assessment instruments}

\section{Anxiety and depression}

The German version of the Hospital Anxiety and Depression Scale (HADS) $[32,33]$ was used to assess anxiety and depression. The questionnaire is designed for patients with somatic diseases and aims to identify typical aspects of anxiety and depression within the previous 7 days. It consists of 14 items and can be divided into two subscales (anxiety and depression) with seven items each. The items can also be summed to a total score, with higher scores indicating larger distress. Values of $0-7,8-10$, and $>11$ in the anxiety subscale and $0-5,6-8$, and $>9$ in the depression subscale are classified as non-cases, probable cases, and cases, respectively [32].

\section{Health-related quality of life}

General HRQOL was assessed using the German Version of the Short-Form-36 Health Survey (SF-36) [34, 35]. The questionnaire consists of 36 items containing eight subscales each. These subscales constitute two higher-level summary scales [the physical (physical function, physical role function, bodily pain, and general health) and psychological (vitality, social function, emotional role function, and mental health) summary scales].

The disease-specific quality of life related to PCOS was evaluated with the Polycystic Ovary Syndrome Questionnaire (PCOSQ; [31, 36]). This questionnaire consists of 26 items that measure five domains of PCOS-specific symptoms within the previous 2 weeks, including emotions ( 8 items), body hair ( 5 items), weight (5 items), infertility problems (4 items), and menstrual problems (4 items). Each question requires an answer on a 7-point Likert scale, with lower scores indicating more impairment. The English version of the PCOSQ was translated into German by a native speaker, translated back into English and then translated back into German. The final version of the PCOSQ-G was constructed from both German versions.

\section{Statistical analysis}

The sociodemographic data and sample characteristics were analyzed using the $\chi^{2}$ test, independent sample $t$ tests and Pearson's correlation coefficient. The psychometric values for the items and the scales were evaluated with corrected item-total correlation ( $r<0.3$ was considered weak), internal consistency (Cronbach's $\alpha$ ) and test-retest reliability (intraclass correlation coefficient, two-way random effect, and absolute agreement; 4-week intervals). The floor and ceiling effects (defined as the highest and lowest 15\% of 
the scale) were calculated for the total score and all subscales. We evaluated the validity of the PCOSQ using correlation analyses with the HADS and the SF-36, including their subscales. The psychometric and validity evaluations were conducted only in the patient sample. To determine the discriminatory validity of the PCOSQ, a receiver operating characteristic (ROC) curve and independent sample $t$ tests were calculated for the patient sample and the control sample. ROC curves are graphical plots of the true positive rate (sensitivity) versus the false positive rate (1-specificity) which allow to distinguish between cases (patients) and non-cases (healthy controls). Clinical differences within the patient sample were investigated using Pearson's correlation coefficients, $t$ tests, and effect size calculations (Cohen's $d$ ). Effect sizes of $d=0.2, d=0.5$, and $d=0.8$ were considered small, medium or large, respectively [37]. Statistical analysis was performed with IBM SPSS (version 21, IBM Corporation, Armonk, NY, USA). $p$ values $<0.05$ were considered significant.

\section{Results}

\section{Sociodemographic and clinical characteristics}

Of the initially approached 199 patients, $n=60$ patients (approximately $30 \%$ response rate) returned completed questionnaires, which was comparable to previous studies [9, 38]. A control group of $n=61$ age-matched women without PCOS was included in the study.

The mean age of the included total sample was 29.7 (SD 6.2) years, $63.6 \%$ had no children. Most of the patients were married or in a stable relationship (72.7\%), and 56.2\% had a university degree or a high school diploma. The samples showed no significant differences in age $(t=0.14, p=0.89)$, body mass index (BMI) $(t=0.21, p=0.84)$, number of children $(t=1.39, p=0.17)$, or education level $\left(\chi^{2}=6.5\right.$, $p=0.16$ ). In the patient sample, significantly more participants were married or in a stable partnership than the participants in the control sample ( 89.8 vs. $\left.59.3 \% ; \chi^{2}=0.001\right)$. For details, see Table 1.

\section{Psychometric properties of the PCOSQ}

The mean total score of the PCOSQ in the patient sample was 4.9 (SD 1.3) points. The patients reported the largest impairment due to irregular menstrual periods (item 8) and late menstrual periods (item 20), whereas fear of cancer (item 14) was not seen as a problem by most women.

No floor or ceiling effects were found for the PCOSQ total score, the emotional subscale, the infertility subscale, and the menstrual problems subscale. Both the hair and weight subscales showed significant ceiling effects, with $33.3 \%$ of the patients scoring the highest possible score on both subscales. Table 2 shows the mean scores and standard deviations for all items, including the item-total correlation for the specific subscales.

Acceptable to high internal consistency at both measurement time points was found for the total score $(\alpha=0.94-0.95)$. All subscales showed satisfactory internal consistencies ( $\alpha=0.70-0.97)$. The corrected item-total correlations with the total score were in the acceptable range $(r=0.38-0.81)$ for all items except for item 20 ('In relation to your last menstruation, how much were late menstrual periods a problem for you?'; $r=0.16$ ), which also showed a weak item-total correlation with the emotional subscale. The exclusion of item 20 resulted in an improved Cronbach alpha for the emotional subscale $(\alpha=0.90)$ but not for the total score.

The intraclass correlation coefficients (test-retest reliability) were high for the total score (0.86) and all subscales (0.81-0.90). For details, see Table 3.

\section{Validity}

As hypothesized, the PCOSQ total score was positively correlated with both SF-36 summary scales and was negatively correlated with both HADS subscales (see Table 4). The construct validity of the PCOSQ emotional subscale was evaluated by comparing its correlations with the SF-36 emotional summary scale and the HADS subscales to the other subscale loadings. As expected, we found a significant correlation between the PCOSQ emotional scale and the SF-36 emotional summary scale $(r=0.042, p=0.001)$, whereas no correlation was found to the SF-36 physical
Table 1 Sociodemographic characteristics of patients and controls

\begin{tabular}{lcccc}
\hline & Patients $(n 1=60)$ & Controls $(n 2=61)$ & $t$ value $/ \chi^{2}$ value & $p$ \\
\hline Mean age (SD) & $29.8(4.6)$ & $29.6(7.3)$ & 0.14 & 0.89 \\
Mean BMI (SD) & $24.6(6.1)$ & $24.4(5.8)$ & 0.21 & 0.84 \\
Married/partnership (\%) & $53(89.8 \%)$ & $35(59.3 \%)$ & 14.83 & 0.001 \\
University degree or high & $32(54.2 \%)$ & $59(59.0 \%)$ & 6.54 & 0.16 \\
$\quad$ school diploma (\%) & $40(66.7 \%)$ & $37(60.7 \%)$ & 4.22 & 0.24 \\
No children (\%) & & & & \\
\hline
\end{tabular}


Table 2 PCOSQ-G items with mean scores, standard deviation, and item-total correlation

\begin{tabular}{|c|c|c|}
\hline & Mean (SD) & $\begin{array}{l}\text { Item-total } \\
\text { correlation }\end{array}$ \\
\hline Total score & $4.9(1.3)$ & \\
\hline Subscale: emotion & $5.0(1.4)$ & \\
\hline \multicolumn{3}{|l|}{ During the last 2 weeks... } \\
\hline $2 \ldots$. how much of the time have you felt depressed as a result of having PCOS? & $5.6(1.7)$ & 0.83 \\
\hline $4 \ldots$. how much of the time have you felt easily tired? & $4.1(1.7)$ & 0.57 \\
\hline 6. ... how much of the time have you felt moody as a result of having PCOS? & $4.9(1.9)$ & 0.77 \\
\hline 11.... how much of the time have you felt you had low self-esteem as a result of having PCOS? & $5.4(2.0)$ & 0.61 \\
\hline $14 \ldots .$. how much of the time have you felt frightened of getting cancer? & $5.9(1.2)$ & 0.39 \\
\hline $17 . .$. to what extent have you worried about having PCOS? & $5.2(2.1)$ & 0.78 \\
\hline 18....to what extent have you been self-conscious as a result of having PCOS? & $5.5(2.0)$ & 0.85 \\
\hline 20. In relation to your last menstruation, how much were late menstrual periods a problem for you? & $3.5(2.4)$ & 0.25 \\
\hline Subscale: body hair & $5.2(2.1)$ & \\
\hline 1. To what extent have you felt that the growth of visible hair on your chin has been a problem for you during the last 2 weeks? & $5.3(2.3)$ & 0.82 \\
\hline 9. To what extent has the growth of visible hair on your upper lip been a problem for you during the last 2 weeks? & $5.0(2.2)$ & 0.86 \\
\hline 15. Over the last 2 weeks, to what extent have the growth of visible hair on your face been a problem for you? & $5.1(2.3)$ & 0.91 \\
\hline 16. Over the last 2 weeks, to what extent has embarrassment about excessive body hair been a problem for you? & $5.3(2.4)$ & 0.88 \\
\hline 26. To what extent has the growth of visible body hair been a problem for you during the last 2 weeks? & $5.0(2.4)$ & 0.92 \\
\hline Subscale: weight concerns & $5.1(2.0)$ & \\
\hline 3. During the past 2 weeks, how much of the time have you felt concerned about being overweight? & $5.1(2.4)$ & 0.91 \\
\hline 10. During the past 2 weeks, how much of the time have you had trouble dealing with your weight? & $4.8(2.3)$ & 0.90 \\
\hline 12. During the past 2 weeks, how much of the time have you felt frustration with trying to lose weight? & $5.0(2.3)$ & 0.93 \\
\hline 22. How much of the time during the last 2 weeks did you feel like you were not sexy because of being overweight? & $5.6(2.0)$ & 0.78 \\
\hline 24. How much of the time during the last 2 weeks did you have difficulties staying at your ideal weight? & $5.1(2.2)$ & 0.81 \\
\hline Subscale: infertility concerns & $4.7(1.8)$ & \\
\hline 5. During the past 2 weeks, how much of the time have you felt concerned with infertility problems? & $4.3(2.1)$ & 0.80 \\
\hline 13. During the past 2 weeks, how much of the time have you felt afraid of not being able to have children? & $4.3(2.4)$ & 0.85 \\
\hline 23. How much of the time during the last 2 weeks did you feel a lack of control over the situation with PCOS? & $5.7(1.8)$ & 0.53 \\
\hline 25. How much of the time during the last 2 weeks did you feel sad because of infertility problems? & $4.5(2.1)$ & 0.84 \\
\hline Subscale: menstrual irregularities & $4.4(1.6)$ & \\
\hline \multicolumn{3}{|l|}{ In relation to your last menstruation... } \\
\hline 7. ... how much were headaches a problem for you? & $5.2(2.1)$ & 0.49 \\
\hline 8. ... how much were irregular menstrual periods a problem for you? & $3.2(2.4)$ & 0.22 \\
\hline $19 . .$. how much was abdominal bloating a problem for you? & $4.6(2.2)$ & 0.59 \\
\hline 21. ... how much were menstrual cramps a problem for you? & $4.5(2.2)$ & 0.72 \\
\hline
\end{tabular}

scale $(r=0.20, p=0.12)$. Furthermore, the correlations of the HADS subscales to the PCOSQ emotional subscale ( $r=0.75-0.79, p<0.001)$ were considerably higher than the correlations to the other PCOSQ subscales $(r=0.35-0.56$,

Table 3 Test-retest reliability of the PCOSQ-G with Cronbach's alpha at two time points

\begin{tabular}{llll}
\hline & $\begin{array}{l}\text { Cronbach } \\
\text { alpha T0 }\end{array}$ & $\begin{array}{l}\text { Cronbach } \\
\text { alpha T1 }\end{array}$ & Test-retest \\
\hline Total score & 0.94 & 0.95 & 0.86 \\
Subscale: emotion & 0.87 & 0.85 & 0.85 \\
Subscale: body hair & 0.96 & 0.97 & 0.86 \\
Subscale: weight concerns & 0.95 & 0.94 & 0.85 \\
Subscale: infertility concerns & 0.89 & 0.92 & 0.81 \\
Subscale: menstrual irregularities & 0.70 & 0.77 & 0.90 \\
\hline
\end{tabular}

$p<0.01)$. The SF-36 physical subscale was significantly correlated with the PCOSQ menstrual irregularities subscale ( $r=0.36, p=0.005)$.

To distinguish the discriminatory validity of the PCOSQ between the patients and healthy controls, independent sample $t$ tests were calculated. Patients reported significantly lower values on the PCOSQ total score $(p<0.001)$ and the scores reflecting their emotional quality of life $(p<0.001)$, body hair ( $p<0.001)$, weight concerns $(p=0.03)$, infertility concerns $(p<0.001)$, and menstrual irregularities $(p<0.001)$. No significant differences between the two groups were found regarding the SF-36 emotional ( $p=0.23$ ) and physical summary scales $(p=0.60)$ nor the HADS anxiety $(p=0.72)$ and depression $(p=0.28)$ subscales. For details, see Table 5 . 
Table 4 Correlation between PCOSQ-G and SF-36/HADS anxiety and HADS depression

\begin{tabular}{lllll}
\hline & $\begin{array}{l}\text { SF-36: emo- } \\
\text { tional summary } \\
\text { scale }\end{array}$ & $\begin{array}{l}\text { SF-36: physical } \\
\text { summary scale }\end{array}$ & HADS anxiety & HADS depression \\
\hline PCOSQ total score & $0.28^{*}$ & $0.29 *$ & $-0.69 * * *$ & $-0.73^{* * *}$ \\
Subscale: emotion & $0.42^{* *}$ & 0.20 & $-0.79 * * *$ & $-0.75^{* * *}$ \\
Subscale: body hair & 0.13 & 0.19 & $-0.44 * * *$ & $-0.56^{* * *}$ \\
Subscale: weight concerns & 0.14 & 0.23 & $-0.41^{* *}$ & $-0.49^{* * *}$ \\
Subscale: infertility concerns & 0.25 & 0.12 & $-0.49 * * *$ & $-0.50^{* * *}$ \\
Subscale: menstrual irregularities & 0.08 & $0.36^{* *}$ & $-0.46^{* * *}$ & $-0.35^{* *}$ \\
\hline
\end{tabular}

$* p<0.05, * * p<0.01, * * * p<0.001$

Table 5 Comparison of the PCOSQ-G, SF-36, and HADS between patients and healthy controls evaluated by independent sample $t$ test

\begin{tabular}{|c|c|c|c|c|c|c|}
\hline & $\begin{array}{l}\text { Patients }(n=60) \\
\text { Mean (SD) }\end{array}$ & $\begin{array}{l}\text { Controls }(n=61) \\
\text { Mean (SD) }\end{array}$ & Mean diff & Cohen's $d$ & $t$ value & $p$ value \\
\hline PCOSQ-G total score & $4.9(1.3)$ & $6.2(0.8)$ & 1.3 & 1.14 & 6.2 & $<0.001$ \\
\hline Subscale: emotion & $5.0(1.4)$ & $6.2(0.8)$ & 1.2 & 0.27 & 5.9 & $<0.001$ \\
\hline Subscale: body hair & $5.2(2.1)$ & $6.4(1.3)$ & 1.3 & 0.27 & 3.9 & $<0.001$ \\
\hline Subscale: weight concerns & $5.1(2.0)$ & $5.8(1.5)$ & 0.7 & 0.17 & 2.2 & 0.03 \\
\hline Subscale: infertility concerns & $4.7(1.8)$ & $6.8(0.4)$ & 2.1 & 1.62 & 8.9 & $<0.001$ \\
\hline Subscale: menstrual irregularities & $4.4(1.6)$ & $5.6(1.3)$ & 1.2 & 0.84 & 4.6 & $<0.001$ \\
\hline SF-36: emotional sum scale & $35.4(6.4)$ & $36.7(5.8)$ & 1.4 & 0.22 & 1.2 & 0.23 \\
\hline SF-36: physical sum scale & $50.7(9.3)$ & $51.7(9.8)$ & 0.9 & 0.10 & 0.5 & 0.60 \\
\hline HADS: anxiety & $5.9(3.8)$ & $5.7(3.1)$ & 0.2 & 0.07 & 0.3 & 0.72 \\
\hline HADS: depression & $3.3(3.6)$ & $4.1(4.3)$ & 0.8 & 0.19 & 1.1 & 0.28 \\
\hline
\end{tabular}

To further investigate the discriminatory validity, we calculated ROC curves with the PCOSQ total score as the test variable. The area under the curve was $\mathrm{AUC}=0.81$ $(p<0.001 ; 95 \%$ CI 0.73-0.89) (see Fig. 1).

\section{Clinical data}

Patients with partners with a pathological semen analysis ( $N=19$ vs $N=22$ with normal semen analysis) were significantly less concerned about infertility $(t=2.1$, $p=0.043, d=0.65$ ), whereas no significant differences were found regarding the other PCOSQ subscales, the SF-36 summary scales or anxiety and depression. We also investigated correlations between the BMI and the PCOSQ subscales and found that higher BMI values were significantly correlated with more emotional distress $(r=0.37, p=0.004)$, more problems with body hair $(r=0.38, p=0.003)$, and more infertility concerns $(r=0.35, p=0.007)$. No significant relationship with menstrual problems $(p=0.16)$ was found.

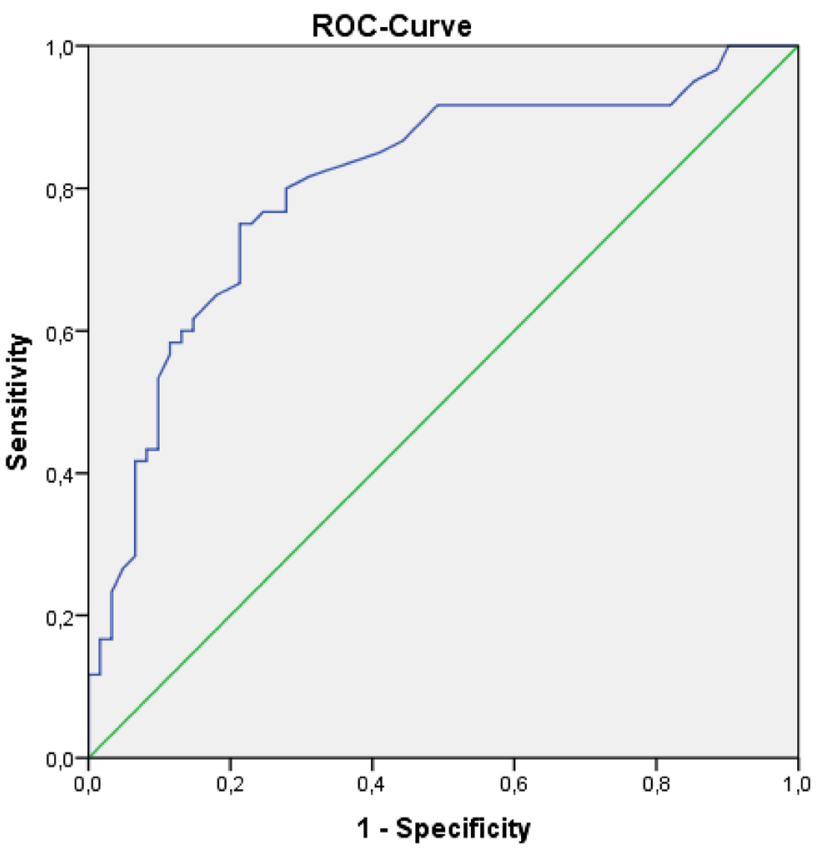

Fig. 1 Receiver operating characteristic curve with the area under the curve for discriminator validity 


\section{Discussion}

The objective of this study was to validate and establish the German version of the disease-specific PCOSQ questionnaire and to assess anxiety and depression symptoms and the HRQOL in patients with PCOS. Our analyses showed satisfying psychometric properties and good internal consistency and retest reliability values. The patients reported significantly higher impairment on the emotion, body hair, infertility, menstrual problems, and weight domains than the healthy controls. This finding is in accordance with the original questionnaire designed by Cronin et al. [31] and with the validation of the Chinese version [39]. The construct validity was tested by comparison with SF-36 as described in former validations $[6,36]$. The absence of floor and ceiling effects indicated that the PCOSQ-G is a well-balanced instrument, which is able to capture different nuances of HRQOL in patients with PCOS. Based on the area under the curve, the PCOSQ-G can also be considered a reliable test to distinguish between patients with PCOS and non-patients. Although we found significant differences between the patients and healthy controls in the PCOSQ-G subscales, no significant differences were observed in depression or general HRQOL as assessed by the SF-36; in other words, the PCOSQ-G revealed differences in the HRQOL that were not revealed using the SF-36.

Our results are in accordance with previous research [30] showing that the PCOSQ reveals more significant differences between the samples than generic distress and QoL measures. Therefore, the present study clearly underscores the importance of a disease-specific instrument for the assessment of the HRQOL. Generic instruments on psychological distress or general QoL may allow comparisons of these variables between patients with different diseases but are vulnerable to underestimation of the more subtle disease-specific impairments.

In the present study, we did not find any differences in anxiety and depression between the patients with PCOS and the healthy controls. This finding is in contrast to previous data showing an increased risk of anxiety and depression in PCOS patients. Benson et al. [5] conducted a large internet-based survey using the HADS and SF-12 questionnaires. Based on self-reported data on the homepage of a self-support group, $34 \%$ of the patients showed high HADS anxiety scores and $21 \%$ showed high HADS depression scores. Using the same questionnaires, an Iranian study found elevated HADS anxiety scores in $32 \%$ of patients but high depression scores in only $5 \%$ of patients [15]. In a cohort of untreated patients without a prior psychiatric diagnosis, $15 \%$ of the sample showed psychological disorders [12]. These findings are in accordance with our results underscoring the impact of the definition of the recruited patient cohort.

Several meta-analyses on this topic have analyzed the prevalence of anxiety and depressive disorders in PCOS patients with inconsistent results depending on the methodologies, sample size, and data collection [7-10]. Most of these studies do not include a healthy control group but compare their findings with reference populations. One of the main aspects criticized by the authors of meta-analyses is that the anxiety and depression scores in PCOS patients may be higher than the scores of the healthy controls but are still within the normal ranges [7-9, 12]. Therefore, the clinical relevance is questionable. This finding was in accordance with our findings since our healthy controls showed similar anxiety and depression scores.

The determinants of mental distress in PCOS patients remain unclear. Clinical features associated with PCOS, such as hirsutism, obesity, or infertility, may be related to higher levels of anxiety and depression, especially because these features interfere with the outer appearance and social norms. The following studies aimed to clarify whether subgroups of patients with these stigmatizing aspects were predisposed to develop severe psychological symptoms.

Hirsutism influences the outer appearance and self-body image. In theory, affected patients should show higher depression scores. The correlation between hyperandrogenism and depression scores remains unclear because conflicting results have been published [9, 13, 14, 22, 23, 25-27]. Interestingly, after 6 months of treatment with an oral contraceptive, hirsutism was significantly improved, but the depression scores remained unchanged [40]. Regarding the HRQOL, hirsutism seems to negatively affect women with PCOS $[18,23,24]$.

A further determinant of mental health in PCOS patients is the $B M I$, although conflicting results have been published [18]. The present study showed higher impairment in nearly all subscales of the PCOSQ in patients with higher BMIs. Higher depression scores and a lower HRQOL were found in obese women with PCOS accompanied by dissatisfaction with their physical appearance [12, 14, 23, 24, 41]. Anxiety symptoms were reported more often in PCOS patients than in controls matched for BMI [28].

The depression scores improved after weight loss due to dietary restrictions and exercise [42]. Nevertheless, persons with a normal weight can also suffer from low body satisfaction. Therefore, the correlation between body image and depression seems to be more relevant than the correlation between BMI and depression [17, 30]. Furthermore, patients with PCOS report worse sexual function and HRQOL, although body weight itself does not influence sexual function [29]. 
An increased risk for clinically relevant anxiety was found in women with PCOS and infertility [5, 12, 43]. Surprisingly, in a study focused on the association between infertility and PCOS, patients wishing to conceive did not show higher impaired psychological functions [44]. Infertility itself is known to have an impact on the HRQOL [45-47]. Within this cohort, women with PCOS who wished to conceive reported a lower HRQOL than women with unexplained infertility [24]. When comparing different phenotypes of women with PCOS and women with unexplained infertility, primary infertility as such and PCOS patients with hyperandrogenism and anovulatory cycles had the lowest scores in the HRQOL [21].

One interesting new finding of the present study is that male infertility also has an impact on the partner's mental health. Patients with a partner with a pathological semen analysis were less concerned about infertility, whereas the scores for anxiety, depression, and the other subscales of the PCOSQ remained unchanged. In a recent study using the fertility-related quality of life (FertiQOL) questionnaire, males with unexplained fertility showed a higher impairment than males with a partner diagnosed with PCOS [24]. This finding underscores the attribution of the cause of infertility to one partner being able to influence the quality of life.

The lack of an acne scale in the PCOSQ has been widely criticized [36, 43]. Several studies underscored the influence of acne on anxiety, depression, and the QoL [48], although another study by the same investigators found no effect of acne on the QoL [23]. The need for an acne scale depends on the group of PCOS patients being interviewed. For instance, patients presenting at dermatology or gynecological endocrinology departments are more likely to suffer from acne symptoms than patients primarily presenting at infertility clinics [36]. Barnard et al. [43] included an acne subscale with four items. A review by Jones et al. [18] showed that acne was a minor concern for the QoL in most studies. Therefore, further study is needed to assess the association between acne and the QoL before an acne subscale is established in the PCOSQ.

The domain of greatest concern in most studies is weight $[18,20]$. In contrast, in the present study, the weight domain showed a ceiling effect. Another meta-analysis [19] revealed hirsutism and menstruation as the most affected domains. In our cohort, menstrual problems were the domain of greatest concern. Our patients were recruited from a fertility clinic. In this context, menstruation is of major importance because it is a marker for ovulation and fertility and determines the timing to initiate a controlled ovarian stimulation cycle. Therefore, menstrual irregularities cause emotional distress and difficulties regarding the timing of becoming pregnant. The absence of menstruation can affect feelings of femininity [19] because the individual and social perception of female functioning may be impaired.

\section{Limitations}

The present study has some limitations. Recruitment of patients took place in a University Clinic of Gynecologic Endocrinology and Reproductive Medicine. Assumingly, the proportion of patients with infertility problems or rather specific impairments might be larger than in the general population. Additionally, the response rate was only $30 \%$ which renders the question whether a certain cohort of the patients-with more or less psychological strain-returned the questionnaires. However, this is a problem inherent to all similar studies. The timeframe of 4 weeks for the retest reliability is rather long and, therefore, prone to changes in individual health over this time period. However, surprisingly good retest reliability was found. This finding raises the question of whether the PCOSQ is sufficiently sensitive to changes. Further research should investigate this aspect. Additionally, the sample size was too small to compare the different proposed factor solutions with confirmatory factor analyses. We chose to use the original factorial structure because several studies confirmed the structure [20, 36, 39, 43, 49]. The six-factor solution proposed in the Swedish study by Jedel et al. [50] was based on a rather small sample size and had not been confirmed to date. Our results indicate that the proposed factorial structure can be used in clinical practice because the subscales seem to be suited to the assessment of different aspects of the HRQOL in patients with PCOS. Nevertheless, future studies should further investigate the factorial structure of the PCOSQ.

\section{Conclusion}

The psychosocial dimension of psychological disorders in PCOS patients remains variable in each individual patient, with a range from normal values up to clinically relevant symptoms of depression and anxiety. Future studies should focus on developing models to identify patients at increased risk for severe psychological disturbances. Because there is a need for a disease-specific questionnaire, the now-validated German version of the PCOSQ-G may help select patients with an impaired HRQOL and consequently a possible higher risk for psychological disorders.

Acknowledgements Open access funding provided by University of Innsbruck and Medical University of Innsbruck.

Author contributions BB: project development, data management, data analysis, manuscript writing. SF: project development, data collection, data analysis, manuscript editing. FF: project development, data analysis, manuscript editing. BT: manuscript editing. MHW: project 
development, data analysis, manuscript editing. LW: project development, data analysis, manuscript editing. DR: data management, data analysis, manuscript writing.

\section{Compliance with ethical standards}

Conflict of interest The authors declare that they have no conflict of interest.

Open Access This article is distributed under the terms of the Creative Commons Attribution 4.0 International License (http://creativecommons.org/licenses/by/4.0/), which permits unrestricted use, distribution, and reproduction in any medium, provided you give appropriate credit to the original author(s) and the source, provide a link to the Creative Commons license, and indicate if changes were made.

\section{References}

1. Azziz R, Woods KS, Reyna R, Key TJ, Knochenhauer ES, Yildiz BO (2004) The prevalence and features of the polycystic ovary syndrome in an unselected population. J Clin Endocrinol Metab 89:2745-2749. https://doi.org/10.1210/jc.2003-032046

2. March WA, Moore VM, Willson KJ, Phillips DIW, Norman RJ, Davies MJ (2010) The prevalence of polycystic ovary syndrome in a community sample assessed under contrasting diagnostic criteria. Hum Reprod 25:544-551. https://doi.org/10.1093/humrep/ dep399

3. Bozdag G, Mumusoglu S, Zengin D, Karabulut E, Yildiz BO (2016) The prevalence and phenotypic features of polycystic ovary syndrome: a systematic review and meta-analysis. Hum Reprod 31:2841-2855. https://doi.org/10.1093/humrep/dew218

4. Rotterdam ESHRE/ASRM-Sponsored PCOS Consensus Workshop Group (2004) Revised 2003 consensus on diagnostic criteria and long-term health risks related to polycystic ovary syndrome. Fertil Steril 81:19-25

5. Benson S, Hahn S, Tan S, Mann K, Janssen OE, Schedlowski M, Elsenbruch S (2009) Prevalence and implications of anxiety in polycystic ovary syndrome: results of an internet-based survey in Germany. Hum Reprod 24:1446-1451. https://doi.org/10.1093/ humrep/dep031

6. Coffey S, Bano G, Mason HD (2006) Health-related quality of life in women with polycystic ovary syndrome: a comparison with the general population using the Polycystic Ovary Syndrome Questionnaire (PCOSQ) and the Short Form-36 (SF-36). Gynecol Endocrinol 22:80-86. https://doi. org/10.1080/09513590600604541

7. Cooney LG, Lee I, Sammel MD, Dokras A (2017) High prevalence of moderate and severe depressive and anxiety symptoms in polycystic ovary syndrome: a systematic review and meta-analysis. Hum Reprod 32:1075-1091. https://doi.org/10.1093/humrep/ dex044

8. Veltman-Verhulst SM, Boivin J, Eijkemans MJC, Fauser BJCM (2012) Emotional distress is a common risk in women with polycystic ovary syndrome: a systematic review and meta-analysis of 28 studies. Hum Reprod Update 18:638-651. https://doi. org/10.1093/humupd/dms029

9. Barry JA, Kuczmierczyk AR, Hardiman PJ (2011) Anxiety and depression in polycystic ovary syndrome: a systematic review and meta-analysis. Hum Reprod 26:2442-2451. https://doi. org/10.1093/humrep/der197

10. Blay SL, Aguiar JVA, Passos IC (2016) Polycystic ovary syndrome and mental disorders: a systematic review and exploratory meta-analysis. Neuropsychiatr Dis Treat 12:2895-2903. https:// doi.org/10.2147/NDT.S91700
11. Cipkala-Gaffin J, Talbott EO, Song M-K, Bromberger J, Wilson J (2012) Associations between psychologic symptoms and life satisfaction in women with polycystic ovary syndrome. J Womens Health (Larchmt) 21:179-187. https://doi.org/10.1089/ jwh.2010.2541

12. Elsenbruch S, Benson S, Hahn S, Tan S, Mann K, Pleger K, Kimmig R, Janssen OE (2006) Determinants of emotional distress in women with polycystic ovary syndrome. Hum Reprod 21:10921099. https://doi.org/10.1093/humrep/dei409

13. Hollinrake E, Abreu A, Maifeld M, Van Voorhis BJ, Dokras A (2007) Increased risk of depressive disorders in women with polycystic ovary syndrome. Fertil Steril 87:1369-1376. https://doi. org/10.1016/j.fertnstert.2006.11.039

14. Pastore LM, Patrie JT, Morris WL, Dalal P, Bray MJ (2011) Depression symptoms and body dissatisfaction association among polycystic ovary syndrome women. J Psychosom Res 71:270-276. https://doi.org/10.1016/j.jpsychores.2011.02.005

15. Bazarganipour F, Ziaei S, Montazeri A, Foroozanfard F, Kazemnejad A, Faghihzadeh S (2013) Psychological investigation in patients with polycystic ovary syndrome. Health Qual Life Outcomes 11:141. https://doi.org/10.1186/1477-7525-11-141

16. Hung J-H, Hu L-Y, Tsai S-J, Yang AC, Huang M-W, Chen P-M, Wang S-L, Lu T, Shen C-C (2013) Risk of psychiatric disorders following polycystic ovary syndrome: a nationwide populationbased cohort study. PLoS ONE 9:e97041. https://doi.org/10.1371/ journal.pone.0097041

17. Deeks AA, Gibson-Helm ME, Paul E, Teede HJ (2011) Is having polycystic ovary syndrome a predictor of poor psychological function including anxiety and depression? Hum Reprod 26:1399 1407. https://doi.org/10.1093/humrep/der071

18. Jones GL, Hall JM, Balen AH, Ledger WL (2008) Health-related quality of life measurement in women with polycystic ovary syndrome: a systematic review. Hum Reprod Update 14:15-25. https://doi.org/10.1093/humupd/dmm030

19. Bazarganipour F, Taghavi SA, Montazeri A (2015) The impact of polycystic ovary syndrome on the health-related quality of life: a systematic review and meta-analysis. Iran J Reprod Med. 13(2):61-70

20. McCook JG, Reame NE, Thatcher SS (2004) Health-related quality of life issues in women with polycystic ovary syndrome. J Obstet Gynecol Neonatal Nurs 34:12-20. https://doi. org/10.1177/0884217504272945

21. Dilbaz B, Cınar M, Ozkaya E, Tonyalı NV, Dilbaz S (2012) Health related quality of life among different PCOS phenotypes of infertile women. J Turk Ger Gynecol Assoc 13:247-252. https://doi. org/10.5152/jtgga.2012.39

22. Elsenbruch S, Hahn S, Kowalsky D, Offner AH, Schedlowski M, Mann K, Janssen OE (2003) Quality of life, psychosocial wellbeing, and sexual satisfaction in women with polycystic ovary syndrome. J Clin Endocrinol Metab 88:5801-5807. https://doi. org/10.1210/jc.2003-030562

23. Hahn S, Janssen OE, Tan S, Pleger K, Mann K, Schedlowski M, Kimmig R, Benson S, Balamitsa E, Elsenbruch S (2005) Clinical and psychological correlates of quality-of-life in polycystic ovary syndrome. Eur J Endocrinol 153:853-860. https://doi. org/10.1530/eje.1.02024

24. Santoro N, Eisenberg E, Trussell JC, Craig LB, Gracia C, Huang $\mathrm{H}$, Alvero R, Casson P, Christman G, Coutifaris C, Diamond M, Jin S, Legro RS, Robinson RD, Schlaff WD, Zhang H, Investigators Reproductive Medicine Network (2016) Fertility-related quality of life from two RCT cohorts with infertility: unexplained infertility and polycystic ovary syndrome. Hum Reprod 31:22682279. https://doi.org/10.1093/humrep/dew175

25. Klimczak D, Szlendak-Sauer K, Radowicki S (2014) Depression in relation to biochemical parameters and age in women with 
polycystic ovary syndrome. Eur J Obstet Gynecol 184:43-47. https://doi.org/10.1016/j.ejogrb.2014.10.028

26. Annagür BB, Tazegül A, Uguz F, Kerimoglu ÖS, Tekinarslan E, Celik Ç (2013) Biological correlates of major depression and generalized anxiety disorder in women with polycystic ovary syndrome. J Psychosom Res 74:244-247. https://doi.org/10.1016/j. jpsychores.2013.01.002

27. Barry JA, Hardiman PJ, Saxby BK, Kuczmierczyk A (2011) Testosterone and mood dysfunction in women with polycystic ovarian syndrome compared to subfertile controls. J Psychosom Obstet Gynaecol 32:104-111. https://doi.org/10.3109/01674 82X.2011.568129

28. Jedel E, Waern M, Gustafson D, Landen M (2010) Anxiety and depression symptoms in women with polycystic ovary syndrome compared with controls matched for body mass index. Hum Reprod 25(2):450-456. https://doi.org/10.1093/humrep/dep384 (Epub 2009 Nov 19)

29. Benetti-Pinto CL, Ferreira SR, Antunes A, Yela DA (2015) The influence of body weight on sexual function and quality of life in women with polycystic ovary syndrome. Arch Gynecol Obstet 291:451-455. https://doi.org/10.1007/s00404-014-3423-1

30. Panico A, Messina G, Lupoli GA, Lupoli R, Cacciapuoti M, Moscatelli F, Esposito T, Villano I, Valenzano A, Monda V, Messina A, Precenzano F, Cibelli G, Monda M, Lupoli G (2017) Quality of life in overweight (obese) and normal-weight women with polycystic ovary syndrome. Patient Prefer Adherence 11:423-429. https://doi.org/10.2147/PPA.S119180

31. Cronin L, Guyatt G, Griffith L, Wong E, Azziz R, Futterweit W, Cook D, Dunaif A (1998) Development of a health-related quality-of-life questionnaire (PCOSQ) for women with polycystic ovary syndrome (PCOS). J Clin Endocrinol Metab 83:1976-1987. https://doi.org/10.1210/jcem.83.6.4990

32. Herrmann-Lingen C, Buss U, Snaith RP (2011) Hospital anxiety and depression scale: HADS-D; deutsche version. Verlag Hans Huber, Bern

33. Zigmond AS, Snaith RP (1983) The hospital anxiety and depression scale. Acta Psychiatr Scand 67:361-370

34. Morfeld M, Kirchberger I, Bullinger M (2011) SF-36 Fragebogen zum Gesundheitszustand. Hogrefe, Göttingen

35. Ware JE, Sherbourne CD (1992) The MOS 36-item short-form health survey (SF-36). I. Conceptual framework and item selection. Med Care 30:473-483

36. Jones GL, Benes K, Clark TL, Denham R, Holder MG, Haynes TJ, Mulgrew NC, Shepherd KE, Wilkinson VH, Singh M, Balen A, Lashen H, Ledger WL (2004) The Polycystic Ovary Syndrome Health-Related Quality of Life Questionnaire (PCOSQ): a validation. Hum Reprod 19:371-377

37. Cohen J (1977) Statistical power analysis for the behavioral sciences. Lawrence Erlbaum Associates Inc, Hillsdale

38. Friedl F, Riedl D, Fessler S, Wildt L, Walter M, Richter R, Schüßler G, Böttcher B (2015) Impact of endometriosis on quality of life, anxiety, and depression: an Austrian perspective. Arch Gynecol Obstet 292:1393-1399. https://doi.org/10.1007/ s00404-015-3789-8
39. Lin C-Y, Ou H-T, Wu M-H, Chen P-C (2016) Validation of Chinese Version of Polycystic Ovary Syndrome Health-Related Quality of Life Questionnaire (Chi-PCOSQ). PLoS ONE 11:e0154343. https://doi.org/10.1371/journal.pone.0154343

40. Cinar N, Harmanci A, Demir B, Yildiz BO (2012) Effect of an oral contraceptive on emotional distress, anxiety and depression of women with polycystic ovary syndrome: a prospective study. Hum Reprod 27:1840-1845. https://doi.org/10.1093/humrep/des113

41. Cinar N, Kizilarslanoglu MC, Harmanci A, Aksoy DY, Bozdag G, Demir B, Yildiz BO (2011) Depression, anxiety and cardiometabolic risk in polycystic ovary syndrome. Hum Reprod 26:33393345. https://doi.org/10.1093/humrep/der338

42. Thomson RL, Buckley JD, Lim SS, Noakes M, Clifton PM, Norman RJ, Brinkworth GD (2010) Lifestyle management improves quality of life and depression in overweight and obese women with polycystic ovary syndrome. Fertil Steril 94:1812-1816. https://doi.org/10.1016/j.fertnstert.2009.11.001

43. Barnard L, Ferriday D, Guenther N, Strauss B, Balen AH, Dye L (2007) Quality of life and psychological well being in polycystic ovary syndrome. Hum Reprod 22:2279-2286. https://doi. org/10.1093/humrep/dem108

44. Tan S, Hahn S, Benson S, Janssen OE, Dietz T, Kimmig R, Hesse-Hussain J, Mann K, Schedlowski M, Arck PC, Elsenbruch S (2008) Psychological implications of infertility in women with polycystic ovary syndrome. Hum Reprod 23:2064-2071. https:// doi.org/10.1093/humrep/den227

45. Wischmann T, Korge K, Scherg H, Strowitzki T, Verres R (2012) A 10-year follow-up study of psychosocial factors affecting couples after infertility treatment. Hum Reprod 27:3226-3232. https://doi.org/10.1093/humrep/des293

46. Chachamovich JR, Chachamovich E, Ezer H, Fleck MP, Knauth D, Passos EP (2010) Investigating quality of life and healthrelated quality of life in infertility: a systematic review. J Psychosom Obstet Gynaecol 31:101-110. https://doi.org/10.3109/0167 482X.2010.481337

47. Greil AL, Shreffler KM, Schmidt L, McQuillan J (2011) Variation in distress among women with infertility: evidence from a population-based sample. Hum Reprod 26:2101-2112. https://doi. org/10.1093/humrep/der148

48. Benson S, Janssen OE, Hahn S, Tan S, Dietz T, Mann K, Pleger K, Schedlowski M, Arck PC, Elsenbruch S (2008) Obesity, depression, and chronic low-grade inflammation in women with polycystic ovary syndrome. Brain Behav Immun 22:177-184. https:// doi.org/10.1016/j.bbi.2007.07.003

49. Guyatt G, Weaver B, Cronin L, Dooley JA, Azziz R (2004) Healthrelated quality of life in women with polycystic ovary syndrome, a self-administered questionnaire, was validated. J Clin Epidemiol 57:1279-1287. https://doi.org/10.1016/j.jclinepi.2003.10.018

50. Jedel E, Kowalski J, Stener-Victorin E (2008) Assessment of health-related quality of life: Swedish version of polycystic ovary syndrome questionnaire. Acta Obstet Gynecol Scand 87:13291335. https://doi.org/10.1080/00016340802444762 